\title{
A Comparison of Intrathecal Dexmedetomidine and Fentanyl as Adjuvant to Spinal Bupivacaine in Lower Abdominal and Lower Limb Surgeries- A Double Blind Randomised Study
}

\author{
Rashmi Soori ${ }^{1}$, Gayathri Bhat ${ }^{2}$, Syed Abu Sayeed ${ }^{3}$, Siri Kandavar ${ }^{4}$ \\ ${ }^{1}$ Department of Anaesthesiology, K.S. Hegde Medical Academy, Mangalore, Karnataka, India. ${ }^{2}$ Department of \\ Anaesthesiology, K.S. Hegde Medical Academy, Mangalore, Karnataka, India. ${ }^{3}$ Department of \\ Anaesthesiology, Mahadevappa Rampure Medical College, Kalburgi, Karnataka, India. ${ }^{4}$ Department of \\ Anaesthesiology, K.S. Hegde Medical Academy, Mangalore, Karnataka, India.
}

\section{ABSTRACT}

\section{BACKGROUND}

Spinal anaesthesia is a popular regional anaesthetic technique. Hyperbaric bupivacaine is the most common intrathecally used local anaesthetic. Use of intrathecal adjuncts with local anaesthetic helps to prolong the duration of analgesia and decreases the local anaesthetic dosage. We compared dexmedetomidine and fentanyl as adjuncts to intrathecal hyperbaric bupivacaine.

\section{METHODS}

A randomised double blind control study was conducted on 120 patients posted for elective lower abdominal and lower limb surgery under spinal anaesthesia in a tertiary care hospital. Group A received $2.5 \mathrm{~mL}$ of $0.5 \%$ hyperbaric bupivacaine with $0.5 \mathrm{~mL}$ of $0.9 \%$ saline into the sub-arachnoid space. Group B received $2.5 \mathrm{~mL}$ of $0.5 \%$ hyperbaric bupivacaine with $0.5 \mathrm{~mL}$ of dexmedetomidine $(5 \mu \mathrm{g})$ into subarachnoid space. Group C received $2.5 \mathrm{~mL}$ of $0.5 \%$ hyperbaric bupivacaine with 0.5 $\mathrm{mL}$ of fentanyl $(25 \mu \mathrm{g})$.

\section{RESULTS}

There was a statistically significant drop in HR as early as 25 minutes in the dexmedetomidine group compared to saline group ( $\mathrm{p}=0.033)$; and at 30 minutes in fentanyl group compared to saline group ( $\mathrm{p}=0.015)$. Significant drop in SBP was seen at 30 minutes after the centrineuraxial blockade in the dexmedetomidine group compared to saline group $(\mathrm{p}=0.012)$ and remained so till 180 minutes after the blockade.

\section{CONCLUSIONS}

The combination of $0.5 \%$ hyperbaric bupivacaine with dexmedetomidine $(5 \mu \mathrm{g})$ is better compared to $0.5 \%$ hyperbaric bupivacaine with fentanyl $(25 \mu \mathrm{g})$ or $0.5 \%$ hyperbaric bupivacaine alone in providing analgesia, as the combination offers a convenient, simple, inexpensive, effective and safe means of good post-operative analgesia for lower abdominal \& lower limb surgery.

\section{KEY WORDS}

Intrathecal, Dexmedetomidine, Fentanyl
Corresponding Author: Dr. Gayathri Bhat, Department of Anaesthesiology, K.S. Hegde Medial Academy, Deralakatte, Mangalore, Karnataka, India.

E-mail: gaibhat@gmail.com

DOI: $10.14260 / j e m d s / 2020 / 375$

Financial or Other Competing Interests: None.

How to Cite This Article:

Soori R, Bhat G, Sayeed SA, et al. A comparison of intrathecal dexmedetomidine and fentanyl as adjuvant to spinal bupivacaine in lower abdominal and lower limb surgeries- a double blind randomised study. J. Evolution Med. Dent. Sci. 2020;9(22):1706-1712, DOI: $10.14260 / j e m d s / 2020 / 375$

Submission 06-03-2020,

Peer Review 07-05-2020,

Acceptance 13-05-2020,

Published 01-06-2020.

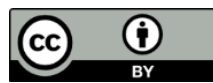




\section{BACKGROUND}

Spinal anaesthesia, also called centrineuraxial blockade, is a type of regional anaesthesia accomplished by injecting the local anaesthetic drug into the subarachnoid space. It is a popular regional anaesthetic technique used for lower abdominal and lower limb surgeries. Spinal anaesthesia alleviates the need for airway manipulation, decreases the risk of aspiration, increase in blood flow to the gut and early return of peristalsis. It also has many benefits like reducing post-operative mortality, deep venous thrombosis, pulmonary embolism, bleeding, and pneumonia. ${ }^{1}$

Bupivacaine is a long-acting, amide local anaesthetic. Bupivacaine contains racemic mixture of (R) - and (S) - stereo isomers. The specific gravity of hyperbaric bupivacaine is between 1.030 and 1.035 at $25^{\circ} \mathrm{C}$. $\mathrm{pH}$ of plain solutions is 4.5 6 and pKa-8.1. Hence only about $15 \%$ of the drug is unionized; the reason for intermediate or slow onset of action. Bupivacaine is highly lipid soluble and is approximately four times more potent than lignocaine. Hyperbaric bupivacaine is the most common intrathecally used local anaesthetic. Its use helps in controlling the level of blockade by tilting the table before the drug is fixed. Use of intrathecal adjuncts with local anaesthetic helps to prolong the duration of analgesia and decrease the local anaesthetic dosage thereby decreasing toxicity. Fentanyl, buprenorphine, clonidine, dexmedetomidine are used as adjuncts in spinal anaesthesia. Fentanyl is a synthetic opioid, 100 to 300 times more potent than morphine. It is primarily a $\mu$ receptor agonist, also binds to a much lesser degree to kappa and delta receptors. In addition to supraspinal sites, fentanyl interacts with opioid receptors in the gray matter of the spinal cord, most of them being located in substantia gelatinosa. Decrease in neurotransmission is the principal effect of opioid receptor activation. Fentanyl also effectively blocks the sympathetic response to stress by suppressing sympathetic outflow in CNS. ${ }^{2}$ Neuraxially administered opioids improve the overall quality of intraoperative analgesia and prolong the duration of postoperative analgesia.

Dexmedetomidine like Clonidine, belongs to imidazole subclass of $\alpha 2$ adrenoceptor agonists. It is the $\mathrm{S}$-enantiomer of medetomidine which is an anaesthetic agent used in veterinary procedures. Dexmedetomidine shows a high ratio of specificity for $\alpha 2$ adrenoceptor ( $\alpha 2 / \alpha 1$ 1600:1) compared to clonidine, making it a complete $\alpha 2$ agonist. ${ }^{2} \alpha 2$ agonists like clonidine and dexmedetomidine are known to have sedative, anxiolytic, hypnotic and opioid sparing effects. $\alpha 2$ agonists when added in centrineuraxial block relieves both somatic and visceral pain. ${ }^{3}$ Dexmedetomidine is being used as a premedication, increasingly used in critical care setting for sedation, to blunt the hemodynamic response during intubation, extubation, laparoscopic surgeries and also as a hypotensive agent under general anaesthesia.

Fentanyl as adjuvant to bupivacaine in spinal anaesthesia is known to prolong the duration of motor and sensory blockade. Similarly, dexmedetomidine is also known to prolong spinal anaesthesia when added with bupivacaine. However, there are sparing studies comparing the haemodynamics, motor and sensory blockade and time to request of first analgesia of fentanyl and dexmedetomidine as adjuvants to bupivacaine in spinal anaesthesia. Therefore; we conducted a study, comparing these effects by adding dexmedetomidine and fentanyl as adjuncts to intrathecal hyperbaric bupivacaine.

\section{METHODS}

The aim of our study was to compare intrathecal $0.5 \%$ hyperbaric bupivacaine combined with normal saline or fentanyl or dexmedetomidine on the onset of sensory block and motor block, haemodynamics including heart rate, systolic, diastolic blood pressure and mean arterial pressure, duration of sensory block, motor block and duration of analgesia.

The study sample size was calculated by

$$
\mathrm{n}=\frac{\left(\mathrm{s}_{1}{ }^{2}+\mathrm{s}_{2}{ }^{2}\right)\left(\mathrm{z}_{1}-\alpha / 2+\mathrm{z}_{1}-\beta\right)^{2}}{\left(\mathrm{x}_{1}-\mathrm{x}_{2}\right)^{2}}
$$

Using the results of $\mathrm{R}$ Gupta et $\mathrm{al}^{4}$ and through the following formula. Considering $\alpha=0.05$, power of $90 \%, n$ (sample size) was calculated as 82 (29 per each group). Considering dropouts and loss to follow up, the sample size was calculated as 40 per group and a total of 120 .

After obtaining approval from the institutional ethical committee, a randomised double blind control study was conducted on 120 patients posted for elective lower abdominal and lower limb surgery under spinal anaesthesia in a tertiary care hospital. The study was conducted from October 2011 to July 2013. Adult patients aged 18-65 years and belonging to American Society of Anaesthesiologists (ASA) physical status I \& II2; scheduled to undergo elective surgery under spinal anaesthesia for lower abdominal and lower limb surgeries were included in the study. Exclusion criteria were patient refusal, patients with known history of sensitivity to the drugs used, ASA physical status III and IV, patients with coagulopathy, infection at the site of the block, neurological deficit of lower extremities, patients on long term analgesics (for more than 1 month), narcotics, antipsychotics.

After obtaining written informed consent, the patients were randomized by closed envelope method into three groups. Group A received $2.5 \mathrm{~mL}$ of $0.5 \%$ hyperbaric bupivacaine with $0.5 \mathrm{~mL}$ of $0.9 \%$ saline into the subarachnoid space. Group B received $2.5 \mathrm{~mL}$ of $0.5 \%$ hyperbaric bupivacaine with $0.5 \mathrm{~mL}$ of dexmedetomidine $(5 \mu \mathrm{g})$ into subarachnoid space. Group C received $2.5 \mathrm{~mL}$ of $0.5 \%$ hyperbaric bupivacaine with $0.5 \mathrm{~mL}$ of fentanyl $(25 \mu \mathrm{g})$.

Pre-operative evaluation included detailed examination and routine preoperative investigations. On the day before surgery after the pre anaesthetic evaluation, patient was informed about the nature of the study and the anaesthetic technique. A written informed consent was taken. Standard anaesthetic regimen was followed in all patients. Patients were kept nil per oral as per the standard guidelines. All patients received premedication with tablet diazepam $5 \mathrm{mg}$ (if weight of the patient was less than or equal to $50 \mathrm{~kg}$ ) or 10 mg (if weight of the patient was more than $50 \mathrm{~kg}$ ) and tablet ranitidine $150 \mathrm{mg}$ orally both $12 \mathrm{hrs}$ and $2 \mathrm{hrs}$ before surgery. After shifting the patient to the operation theatre, 
baseline values of heart rate, blood pressure and oxygen saturation noted.

Intravenous access was secured using a suitable I.V. cannula and crystalloid infusion was started. The first $500 \mathrm{~mL}$ of the crystalloid was run at the rate of $20 \mathrm{ml} / \mathrm{kg} / \mathrm{hr}$ and the subsequent ones at $2 \mathrm{ml} / \mathrm{kg} / \mathrm{hr}$. Subarachnoid block was done under aseptic precautions with patient in sitting position. After local infiltration (with $2 \mathrm{~mL}$ of $2 \%$ lignocaine), lumbar puncture was done using 23 G Quincke Babcock's spinal needle at L3 -L4 interspace and $3 \mathrm{~mL}$ of the test solution loaded by another independent person was injected after confirming free backflow of CSF. Preparation of the test solution was done in a $5 \mathrm{cc}$ syringe containing $2.5 \mathrm{~mL}$ of $0.5 \%$ hyperbaric bupivacaine and $0.5 \mathrm{~mL}$ of normal saline or fentanyl or dexmedetomidine diluted in normal saline $11 \mathrm{~mL}$ of $100 \mu \mathrm{g}$ dexmedetomidine was diluted with $9 \mathrm{~mL}$ of normal saline and $0.5 \mathrm{~mL}$ was used). After intrathecal injection, the patient was repositioned to supine position and oxygen at 5 l/min was supplemented via face mask. The patient was kept in supine position for at least 20 minutes before positioning for surgery. Heart rate, systolic blood pressure, diastolic blood pressure and mean arterial pressure were recorded after subarachnoid blockade initially for every 1 minute for the first 5 minutes, then monitoring was done every 5 minutes till 30 minutes, every 15 minutes till 180 minutes. Level of sensory blockade was assessed using cold alcohol swab along the midclavicular line bilaterally and the higher level was used for statistical purposes. Level was monitored after subarachnoid blockade initially for every 1 minute for the first 5 minutes, then monitoring was done every 5 minutes till 30 minutes, every 15 minutes till peak height of sensory blockade (i.e.; levels had stabilised after three consecutive tests) was achieved. Motor blockade was assessed by asking the patient to flex the lower limbs using Bromage scale (table 1).

\begin{tabular}{|ccc|}
\hline $\begin{array}{c}\text { Grade } \\
\text { I }\end{array}$ & Criteria & Degree of Block \\
II & Just able to flex knees with free movement of & Nil (0\%) \\
& feet & Partial (33\%) \\
III & Unable to flex knees, but with free movement & Almost complete (66\%) \\
IV & Of feet & Complete (100\%) \\
\hline \multicolumn{3}{|c|}{ Table 1. Bromage Scale ${ }^{2}$} \\
\hline
\end{tabular}

Motor blockade was assessed after subarachnoid blockade initially for every 1 minute for the first 5 minutes, then monitoring was done every 5 minutes till 30 minutes, every 15 minutes till complete motor blockade (Bromage scale IV).

Occurrence of side effects like hypotension, bradycardia, nausea, vomiting, shivering, pruritus and respiratory depression (respiratory rate $<8 / \mathrm{min}$ ) were attended and managed accordingly and mentioned in the study sheet. Hypotension defined as systolic blood pressure less than $30 \%$ of the base line or systolic blood pressure less than $90 \mathrm{mmHg}$. It was treated with injection mephentermine $6 \mathrm{mg}$. Bradycardia was defined as heart rate less than $20 \%$ of base line or absolute heart rate less than 40 beats per minute. It was treated with intravenous atropine $0.6 \mathrm{mg}$.

After the completion of surgery, in the post-operative ward, monitoring of haemodynamics was continued and the values were recorded till 180 minutes post spinal. Motor and sensory blockade assessment was continued till motor power returned (regression to Bromage scale I) and sensory block regressed to S1 (ankle joint).

Analgesics were avoided until demanded by the patients. The post-operative nurse was instructed to give injection paracetamol infusion $1 \mathrm{gm}$ over 20 minutes IV at patient's request for analgesia. Post-operative findings like duration of analgesia, time for return of sensory and motor function were all noted and compared between the groups and tabulated for analysis.

Duration of sensory block was defined as period from the onset of sensory loss to the regression of the block to S1 level. Duration of analgesia was defined as period from onset of sensory loss to the time of first analgesic request. Duration of motor block was defined as period from onset of motor block till complete recovery of power of lower limbs (Bromage scale I). ${ }^{5}$

\section{Statistical Analysis}

Statistical analysis was done using Statistical Package for the Social Sciences ver. 16 (IL, Chicago). Analysis of variance (ANOVA) with repeated measures was used to study the differences of continuous variables between the two groups. Posthoc Tukey test was used for inter group comparison of variables. Categorical variables were analyzed with Chisquare test and Fisher exact test. $\mathrm{p}<0.05$ was considered statistically significant.

\section{RESULTS}

In our study, all the three groups were comparable with respect to demographic data (table 2).There was no statistically significant difference in height between saline and dexmedetomidine groups. Although fentanyl group showed a statistically significant difference $(\mathrm{p}=0.011)$, it does not appear to be clinically significant. None of the subjects were excluded from the study.

The haemodynamic characteristics like heart rate $(p=0.899)$, systolic blood pressure $(p=0.199)$, diastolic blood pressure $(p=0.881)$ and mean arterial pressure $(p=0.552)$ were comparable between the three groups from baseline till 15 minutes after the subarachnoid block.

Baseline HR was $83.88 \pm 14.852,82.33 \pm 17.889$ and $83.35 \pm 12.624 \mathrm{bpm}$ in saline, fentanyl and dexmedetomidine groups respectively ( $\mathrm{p}$ value $=0.899$ ).

There was a statistically significant drop in HR as early as 25 minutes in dexmedetomidine group compared to saline group ( $\mathrm{p}$ value $=0.033$ ); and at 30 minutes in fentanyl group compared to saline group ( $\mathrm{p}$ value $=0.015$ ). The significant drop in HR persisted so in both dexmedetomidine and fentanyl group compared to saline group till 180 minutes. However there was no statistically significant difference in HR in dexmedetomidine and fentanyl groups starting from baseline till 180 minutes (figure 1).

Baseline SBP was $127.75 \pm 14.111,138.35 \pm 20.939$ and $131.33 \pm 17.658 \mathrm{~mm} \mathrm{Hg}$ in saline, fentanyl and dexmedetomidine groups respectively ( $P$ value $=0.199$ ). The baseline SBP was comparable between the three groups. SBP values were comparable till 25 minutes after subarachnoid block. There was a significant drop in SBP at 30 minutes after 
the centrineuraxial blockade in the dexmedetomidine group compared to saline group ( $\mathrm{p}$ value $=0.012$ ) and remained so till 180 minutes after the blockade. However the drop in SBP in fentanyl group was comparable with that of saline group throughout the recordings up to 180 minutes after blockade. There was a significant drop in SBP in dexmedetomidine group compared to fentanyl group starting at 45 minutes ( $p$ value $=0.001)$ after blockade to 180 minutes $(\mathrm{p}$ value $=$ 0.022 ) after blockade (figure 2).

Baseline values of MAP were $97.6 \pm 10.572,101.65 \pm 11.731$ and $99.6 \pm 12.524 \mathrm{~mm} \mathrm{Hg}$ in saline, fentanyl and dexmedetomidine groups respectively $(\mathrm{p}$ value $=0.552$ ) Baseline was comparable in all the three groups and remained so till 15 minutes after spinal anaesthesia. There was a significant drop in MAP at 20 minutes in the dexmedetomidine group compared to saline group $(\mathrm{P}$ value $=$ $0.009)$ and remained so till 180 minutes $(p$ value $=0.001)$ There was no significant difference in MAP values between saline and fentanyl group from baseline to 180 minutes after blockade. However compared to fentanyl, the drop in MAP in dexmedetomidine was significant from 45 minutes ( $\mathrm{p}$ value $=$ 0.014) after subarachnoid block to 105 minutes ( $\mathrm{p}$ value $=$ 0.006) after the block; after which the difference was not significant (figure 4).

Baseline DBP were $82.63 \pm 9.545,83.28 \pm 9.454$ and $83.75 \pm 11.061 \mathrm{~mm} \mathrm{Hg}$ in saline, fentanyl and dexmedetomidine groups respectively $(p$ value $=0.881$ ) There was a statistically significant drop in DBP in dexmedetomidine compared to saline group starting at 20 minutes $(p$ value $=0.005)$; remained so till 180 minutes There was no statistically significant difference in DBP between saline and fentanyl group or fentanyl and dexmedetomidine groups from baseline to 180 minutes (figure 3).
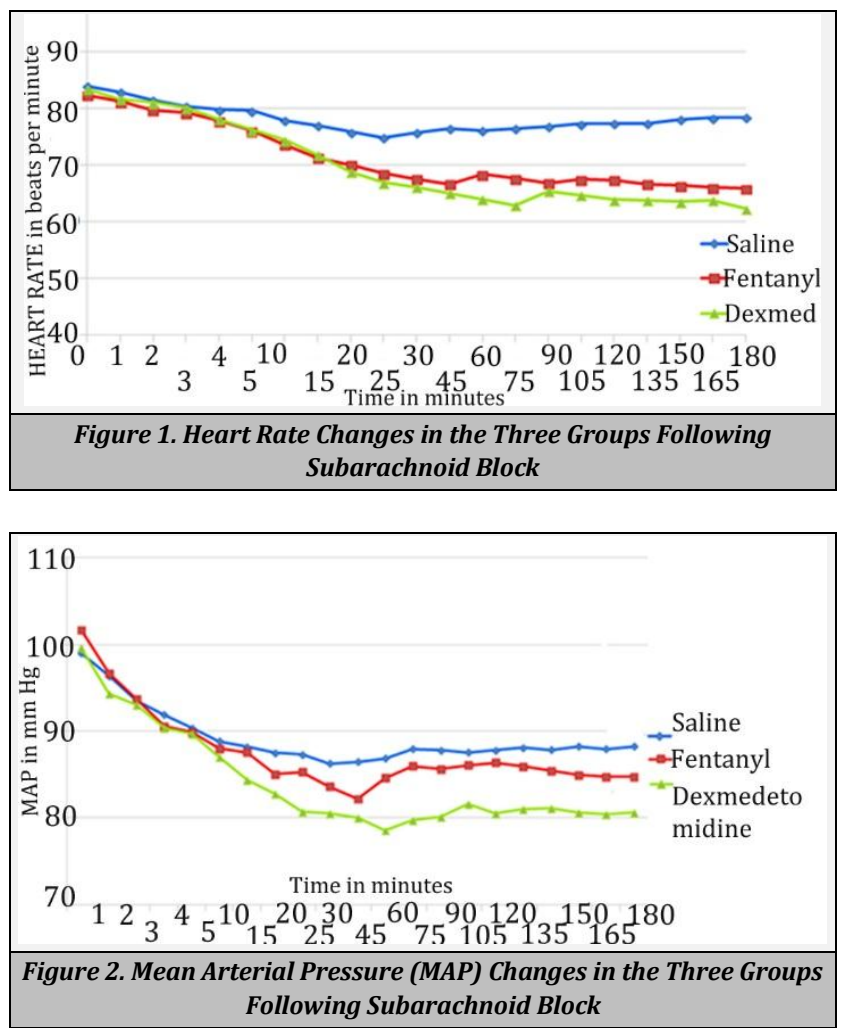

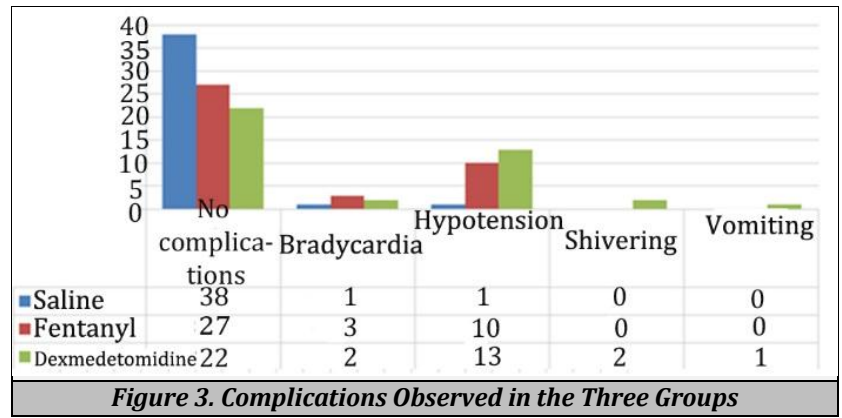

\begin{tabular}{|ccccc|}
\hline $\begin{array}{c}\text { Demographic } \\
\text { Data }\end{array}$ & $\begin{array}{c}\text { Saline } \\
\text { Group }\end{array}$ & $\begin{array}{c}\text { Fentanyl } \\
\text { Group }\end{array}$ & $\begin{array}{c}\text { Dexmedetomidine } \\
\text { Group }\end{array}$ & $\begin{array}{c}\text { p } \\
\text { Value }\end{array}$ \\
Age (yr) & $44.9 \pm 11.202$ & $43.83 \pm 12.341$ & $39.1 \pm 12.326$ & 0.074 \\
Weight $(\mathrm{kg})$ & $56.73 \pm 6.059$ & $55.83 \pm 12.205$ & $57.68 \pm 7.807$ & 0.695 \\
Height (cm) & $159.28 \pm 4.523$ & $156.88 \pm 4.91$ & $159.73 \pm 3.987$ & $0.011^{*}$ \\
Males & 10 & 16 & 11 & 0.298 \\
Females & 30 & 24 & 29 & \\
ASA I (70) & 25 & 24 & 21 & 0.64 \\
ASA II (50) & 15 & 16 & 19 & \\
\hline \multicolumn{5}{|c}{ Table 2. Demographic Data } \\
\hline *Although statistically significant, not clinically significant \\
\hline \multicolumn{5}{|c}{} \\
\hline \multicolumn{5}{|c}{} \\
\hline
\end{tabular}

\section{DISCUSSION}

Dyck et al showed the hemodynamic effects of a bolus of dexmedetomidine in humans have shown a biphasic response. An acute IV injection of $2 \mu \mathrm{g} / \mathrm{kg}$ resulted in an initial increase in blood pressure $(22 \%)$ and decrease in heart rate $(27 \%)$ from baseline that occurred at 5 minutes after injection. This initial increase in blood pressure is probably due to the vasoconstrictive effects of dexmedetomidine when stimulating peripheral $\alpha_{2}$ receptors. ${ }^{2}$ Heart rate returned to baseline by 15 minutes, and blood pressure gradually declined to approximately $15 \%$ below baseline by 1 hour. After an IM injection of the same dose, the initial increase in blood pressure was not seen, and heart rate and blood pressure remained within $10 \%$ of baseline. ${ }^{6}$

Our observation regarding haemodynamics resembles that of IM dexmedetomidine without any biphasic response. This could be due to slow absorption of dexmedetomidine from intrathecal route.

In the dexmedetomidine group, although there was a significant drop in SBP and MAP, HR and DBP were maintained similar to fentanyl group. Hence dexmedetomidine could be beneficial in patients with ischemic heart disease. ${ }^{7}$

Nethra et al showed that there was no statistically significant difference in haemodynamics between control and dexmedetomidine $(5 \mu \mathrm{g})$ as an adjunct to $1.2 \mathrm{~mL}$ of hyperbaric bupivacaine. ${ }^{8}$ Observed difference between their findings and our results could be due to the small dose of bupivacaine used and patient made to sit for $5 \mathrm{~min}$ after subarachnoid block.

Onset of sensory blockade defined as 'time from subarachnoid block to peak height' in saline group was $8.33 \pm$ 5.394 minutes, in fentanyl group was $3.78 \pm 2.315$ minutes and in dexmedetomidine group was $4.65 \pm 4.324$ minutes respectively. Our study shows that adjuvants like fentanyl or dexmedetomidine, decrease the time required to reach peak height compared to the control (saline) group ( $p$ value $<0.001$ ).These results are consistent with that of Naaz et al who compared saline and $5 \mu \mathrm{g}$ dexmedetomidine as additives 
to $2.5 \mathrm{~mL} 0.5 \%$ hyperbaric bupivacaine. ${ }^{9}$ However there was no statistically significant difference in onset of sensory blockade between fentanyl and dexmedetomidine groups ( $p$ value $=0.573$ ). Our observation is consistent with that of with that of Gupta et al comparing $5 \mu \mathrm{g}$ dexmedetomidine and $25 \mu \mathrm{g}$ fentanyl as adjuvant to $2.5 \mathrm{~mL}$ of $0.5 \%$ hyperbaric bupivacaine and showed there was no statistically significant difference in the onset of sensory blockade. 4

Kanazi et al compared $12 \mathrm{mg}$ of hyperbaric bupivacaine, $12 \mathrm{mg}$ of bupivacaine supplemented with $3 \mu \mathrm{g}$ of dexmedetomidine and $12 \mathrm{mg}$ of bupivacaine supplemented with $30 \mu \mathrm{g}$ of clonidine. Patients in both groups did not show any statistically significant difference in onset of sensory blockade compared to control group. This difference compared to our study could be due to smaller dose of dexmedetomidine $(3 \mu \mathrm{g})$ used in the study compared to $5 \mu \mathrm{g}$ used in our study. ${ }^{10}$

Onset of motor blockade defined as the 'time from the subarachnoid blockade till the time required in attaining Bromage IV'. Onset of motor blockade in saline group was $6.28 \pm 5.184$ minutes, in fentanyl group was $3.63 \pm 1.39$ minutes and in dexmedetomidine group was $2.93 \pm 0.829$ minutes. The onset of motor blockade was faster in dexmedetomidine ( $\mathrm{p}$ value $<0.001$ ) and fentanyl groups ( $\mathrm{p}$ value $=0.001$ ) compared to control. These findings are similar to that of Kanazi et al, Sudheesh et al and Sadalla et al.10,11,12 However, there was no statistically significant difference in onset of motor blockade between dexmedetomidine and fentanyl groups. This finding is consistent with that of Gupta et al who showed there was no statistically significant difference in the onset of motor blockade between fentanyl and dexmedetomidine. ${ }^{4}$

Shukla et al compared $15 \mathrm{mg}$ hyperbaric bupivacaine plus $0.1 \mathrm{~mL}$ of saline, dexmedetomidine $(10 \mu \mathrm{g})$ and magnesium sulphate $(50 \mathrm{mg}$ ) showed onset time of block, both sensory and motor, was rapid in the dexmedetomidine group in comparison with the control group. This finding is consistent with our observations. ${ }^{13}$

Al Mustaffa et al studied $12.5 \mathrm{mg} 0.5 \%$ isobaric bupivacaine with normal saline, $10 \mu \mathrm{g}$ dexmedetomidine and $15 \mu \mathrm{g}$ dexmedetomidine. Onset of motor and sensory blockade was faster compared to the control group in a dose dependant manner; which is consistent with our study. ${ }^{14}$

There was a significant drop in HR 25 minutes after subarachnoid block $(p$ value $=0.033$ ) and drop in SBP 30 minutes after subarachnoid block ( $p$ value $=0.012$ ) in dexmedetomidine group compared to saline group. These results are consistent with the findings of Naaz et al. ${ }^{9}$ However, the results of Rai et al showed a drop in haemodynamics as early as 10 minutes after centrineuraxial blockade which gradually returned to normal by the end of surgery. The difference is possibly because they have compared two different doses of dexmedetomidine $(3 \mu \mathrm{g}$ and $5 \mu \mathrm{g}$ ) as additives and not compared with the control group. 15

Duration of sensory blockade defined as the 'duration from the subarachnoid block to the regression of the sensory level of blockade to S1' in saline group was $189.75 \pm 21.09$ minutes, in fentanyl group was $219.38 \pm 30.323$ minutes and in dexmedetomidine group was $348.38 \pm 37.44$ minutes. The sensory regression between the three groups was statistically significant $(\mathrm{P}$ value $<0.001)$. This finding is consistent with that observed with Gupta et al who showed the mean time of sensory regression to S1 was $476 \pm 23 \mathrm{~min}$ in dexmedetomidine group and $187 \pm 12$ min in fentanyl group $(\mathrm{p}<0.001)^{4}$

Shukla et al showed that additives like dexmedetomidine $(10 \mu \mathrm{g})$ and magnesium (50 mg) caused a significantly longer sensory blockade compared to control group (15 mg hyperbaric bupivacaine) which is similar to our study. ${ }^{13}$

Duration of motor blockade defined as the 'duration from subarachnoid blockade till regression to Bromage scale I' in the saline group was $184.5 \pm 19.572$ minutes, in fentanyl group was $209.25 \pm 30.562$ minutes and dexmedetomidine group was $343.88 \pm 35.85$ minutes respectively. Our study shows that fentanyl group prolongs the motor blockade compared to control group $(\mathrm{p}$ value $=0.001)$. Dexmedetomidine prolongs the duration of motor blockade compared to saline ( $\mathrm{p}$ value $<0.001$ ) and fentanyl ( $\mathrm{p}$ value < 0.001 ) groups respectively. This finding is similar to the observations done by Gupta et al, regression time of motor block to reach modified Bromage 0 was $421 \pm 21$ min in dexmedetomidine group and $149 \pm 18$ min in fentanyl group $(\mathrm{p}<0.001) .4$

Shaik et al showed that 'time to reach Bromage 0' was statistically longer with dexmedetomidine $10 \mu \mathrm{g}$ as additive compared to dexmedetomidine $5 \mu \mathrm{g}$ and control (hyperbaric bupivacaine $3 \mathrm{ml}$ ) group ( $\mathrm{p}$ value<0.05). ${ }^{16}$ These results are consistent with our finding.

Shukla et al showed that adjuvants like dexmedetomidine $(10 \mu \mathrm{g})$ and magnesium (50 mg) caused a significantly longer motor blockade compared to control (15 mg hyperbaric bupivacaine) group which is similar to our study. ${ }^{13}$

Hala E A Eid et al compared $3.5 \mathrm{~mL}$ spinal drug that consisted of $3 \mathrm{~mL} 0.5 \%$ hyperbaric bupivacaine and $0.5 \mathrm{~mL}$ containing either $10 \mu \mathrm{g}$ dexmedetomidine (group D1), $15 \mu \mathrm{g}$ dexmedetomidine (D2) or normal saline (group B). Their study showed that there was a dose dependant prolongation of the duration of sensory and motor block by the addition of intrathecal dexmedetomidine. Similar observations were also made by Al Mustafa et al. Our results are consistent with this finding. ${ }^{17}$

According to Kanazi et al, the combination of $12 \mathrm{mg}$ of intrathecal bupivacaine with a low dose of $3 \mu \mathrm{g}$ of dexmedetomidine or $30 \mu \mathrm{g}$ of clonidine significantly prolonged both motor and sensory block when compared with bupivacaine alone. ${ }^{10}$

Maharani et al showed that sensory and motor block parameters achieved with dexmedetomidine $(10 \mu \mathrm{g})$ with 15 mg bupivacaine was statistically significant than with buprenorphine $(60 \mu \mathrm{g})$ with bupivacaine and bupivacaine alone. These findings are consistent with our results. ${ }^{18}$

Time for request of analgesia was $184.5 \pm 19.572$ minutes in saline group, $209.25 \pm 30.562$ minutes in fentanyl group and $343.88 \pm 35.85$ minutes in dexmedetomidine group respectively. Duration for request of analgesia between the three groups was statistically significant ( $p$ value $<0.001$ ). This could be attributed to high dexmedetomidine concentration in the vicinity of $\alpha_{2}$ adrenoreceptors in the spinal cord which works by blocking the conduction of $\mathrm{C}$ and A $\delta$ fibers, increases potassium conductance in isolated neurons in vitro and intensifies conduction block of local anaesthetics. ${ }^{19,20}$ 
Similar observations were made by Gupta et al who showed the time to rescue analgesic was significantly longer in group $\mathrm{D}(2.5 \mathrm{~mL}$ of $0.5 \%$ bupivacaine with $5 \mu \mathrm{g}$ dexmedetomidine) as compared to group $\mathrm{F}$ ( $2.5 \mathrm{~mL}$ of $0.5 \%$ bupivacaine with $25 \mu \mathrm{g}$ fentanyl). The requirement of diclofenac in the first $24 \mathrm{hrs}$ was significantly lower in group D as compared to group F. ${ }^{4}$

Hala E A Eid et al showed that Group D2 $(0.5 \%$ bupivacaine with $15 \mu \mathrm{g}$ dexmedetomidine) had a significantly longer time to first analgesic requirement than both group B $(0.5 \%$ bupivacaine with normal saline) and group D1 $0.5 \%$ bupivacaine with $10 \mu \mathrm{g}$ dexmedetomidine) and group D1 had a significantly longer time to first analgesic requirement than group B. Addition of $10 \mu \mathrm{g}$ or $15 \mu \mathrm{g}$ increased the duration of analgesia. ${ }^{17}$

Deepika Shukla et al showed that $10 \mu \mathrm{g}$ of dexmedetomidine as adjuvant to spinal bupivacaine in surgical procedures of long duration provides excellent quality of postoperative analgesia. Intrathecal magnesium also prolongs the duration of spinal analgesia, but this is less than intrathecal dexmedetomidine. ${ }^{13}$

Kaur et al showed that addition of buprenorphine $(60 \mu \mathrm{g})$ or dexmedetomidine ( $5 \mu \mathrm{g}$ ) to $1.8 \mathrm{~mL}$ of $0.5 \%$ hyperbaric bupivacaine prolonged the duration of analgesia as compared to control group (saline $0.2 \mathrm{~mL}$ ). ${ }^{21}$ This observation is consistent with our results. However our results show that duration to first analgesic requirement is prolonged in dexmedetomidine than fentanyl group. The difference in observation could be due to difference in the invasiveness of the procedure.

Complications occurred in 33 patients out of the 120 study subjects. Bradycardia occurred in 1 patient $(2.5 \%)$ in saline, 3 patients $(7.5 \%)$ in fentanyl and 2 patients $(5 \%)$ in dexmedetomidine groups respectively. Hypotension occurred in 1 patient $(2.5 \%)$ in saline, 10 patients $(25 \%)$ in fentanyl and 13 patients (32\%) in dexmedetomidine groups respectively. Statistical evaluation was done by Chi square test which showed that the occurred complications are statistically significant $(p$ value $=0.001)$.Our results are consistent with that observed by Singh $\mathrm{H}$ et al who compared between $13.5 \mathrm{mg}$ hyperbaric bupivacaine $0.75 \%+0.5 \mathrm{~mL}$ CSF intrathecally (group I) or $13.5 \mathrm{mg}$ hyperbaric bupivacaine $0.75 \%+25 \mu \mathrm{g}$ fentanyl intrathecally (group II) and showed that episodes of hypotension were more frequent in the fentanyl-treated group than in the control group $(p<0.05) .{ }^{22}$

Shivering occurred in 2 patients $(5 \%)$ in dexmedetomidine group. Both the patients were found to undergo urological procedure. Shivering could be attributed to urinary tract infection. No other patient had this complication. 1 patient (2.5\%) in dexmedetomidine group had vomiting. The complications observed by Akhtar et al were also more in the dexmedetomidine than the control group. ${ }^{23}$ However, they were not statistically significant.

Dexmedetomidine as an adjunct to hyperbaric bupivacaine causes prolonged sensory and motor blockade. Hemodynamically intrathecal dexmedetomidine with $0.5 \%$ hyperbaric bupivacaine showed no difference in HR and DBP; however SBP and MAP showed a tendency to fall compared to that of intrathecal fentanyl with $0.5 \%$ hyperbaric bupivacaine. So dexmedetomidine can be effectively used with intrathecal $0.5 \%$ hyperbaric bupivacaine for prolonged procedures involving lower limb and lower abdomen.

\section{CONCLUSIONS}

The combination of $0.5 \%$ hyperbaric bupivacaine with dexmedetomidine $(5 \mu \mathrm{g})$ is better compared to $0.5 \%$ hyperbaric bupivacaine with fentanyl (25 $\mu \mathrm{g}$ ) or $0.5 \%$ hyperbaric bupivacaine alone in providing analgesia, as the combination offers a convenient, simple, inexpensive, effective and safe means of good post-operative analgesia for lower abdominal \& lower limb surgery.

\section{REFERENCES}

[1] Rodgers A, Walker N, Schug S, et al. Reduction of postoperative mortality and morbidity with epidural or spinal anaesthesia: results from overview of randomised trials. BMJ 2000;321(7275):1493.

[2] Eriksson LI. Miller's Anesthesia. $7^{\text {th }}$ edn. Philadelphia: Elsevier Health Sciences 2009.

[3] McNamee DA, Convery PN, Milligan KR. Total knee replacement: a comparison of ropivacaine and bupivacaine in combined femoral and sciatic block. Acta Anaesthesiologica Scandinavica 2001;45(4):477-81.

[4] Gupta R, Verma R, Bogra J, et al. A Comparative study of intrathecal dexmedetomidine and fentanyl as adjuvants to bupivacaine. J Anaesthesiol Clin Pharmacol 2011;27(3):339-43.

[5] Bromage PR. Epidural analgesia. Philadelphia: W.B. Saunders 1978: p. 144.

[6] Dyck JB, Maze M, Haack C, et al. Computer-controlled infusion of intravenous dexmedetomidine hydrochloride in adult human volunteers. Anesthesiology 1993;78(5):821-8.

[7] Nishina K, Mikawa K, Uesugi T, et al. Efficacy of clonidine for prevention of perioperative myocardial ischemia: a critical appraisal and meta-analysis of the literature. Anesthesiology 2002;96(2):323-9.

[8] Nethra SS, Sathesha M, Dixit A, et al. Intrathecal dexmedetomidine as adjuvant for spinal anaesthesia for perianal ambulatory surgeries: a randomised doubleblind controlled study. Indian Journal of Anaesthesia 2015;59(3):177-81.

[9] Naaz S, Bandey J, Ozair E, et al. Optimal dose of intrathecal dexmedetomidine in lower abdominal surgeries in average Indian adult. Journal of Clinical and Diagnostic Research 2016;10(4):UC09-13.

[10] Kanazi GE, Aouad MT, Jabbour-Khoury SI, et al. Effect of low-dose dexmedetomidine or clonidine on the Characteristics of Bupivacaine Spinal Block. Acta Anaesthesiol Scand 2006;50(2):222-7.

[11] Saadalla AET, Khalifa OYA. Influence of addition of dexmedetomidine or fentanyl to bupivacaine lumber spinal subarachnoid anesthesia for inguinal hernioplasty. Anesthesia Essays and Researches 2017;11(3):554-7.

[12] Sudheesh K, Rao RR, Kavya M, et al. Comparative study of two doses of intrathecal dexmedetomidine as adjuvant 
with low dose hyperbaric bupivacaine in ambulatory perianal surgeries: a prospective randomised controlled study. Indian Journal of Anaesthesia 2015;59(10):64852.

[13] Shukla D, Verma A, Agarwal, et al. Comparative study of intrathecal dexmedetomidine with intrathecal magnesium sulfate used as adjuvants to bupivacaine. J Anesthesiol Clin Pharmacol 2011;27(4):495-9.

[14] Al-Mustafa MM, Abu-Halaweh SA, Aloweidi AS, et al. Effect of dexmedetomidine added to spinal bupivacaine for urological procedure. Saudi Med J 2009;30(3):36570.

[15] Rai A, Bhutia MP. Dexmedetomidine as an additive to spinal anaesthesia in orthopaedic patients undergoing lower limb surgeries: a randomized clinical trial comparing two different doses of dexmedetomidine. Journal of Clinical and Diagnostic Research 2017;11(4):UC09-12.

[16] Shaikh SI, Dattatri R. Dexmedetomidine as an adjuvant to hyperbaric spinal bupivacaine for infra-umbilical procedures: a dose related study. Anaesthesia, Pain \& Intensive Care 2014;28:180-5.

[17] Hala EA, Eid MD, Mohamed A, et al. Dose related prolongation of hyperbaric bupivacaine spinal anaesthesia by dexmedetomidine. Ain Shams Journal of Anaesthesiol 2011;4:83-95.
[18] Maharani B, Prakash MS, Kalaiah P, et al. Dexmedetomidine and buprenorphine as adjuvant to spinal anaesthesia-a comparative study. International Journal of Current Research and Review 2013;5(11):104-10.

[19] Chiari A, Eisenach JC. Spinal anaesthesia: mechanisms, agents, methods and safety. Reg Anesth Pain Med 1998;23(4):357-62.

[20] Reddy SV, Yaksh TL. Spinal noradrenergic terminal system mediates antinociception. Brain Res 1980;189(2):391-401.

[21] Kaur N, Goneppanavar U, Venkateswaran R, et al. Comparative effects of buprenorphine and dexmedetomidine as adjuvants to bupivacaine spinal anaesthesia in elderly male patients undergoing transurethral resection of prostrate: a randomized prospective study. Anesthesia Essays and Researches 2017;11(4):886-91.

[22] Singh H, Yang J, Thornton K, et al. Intrathecal fentanyl prolongs sensory bupivacaine spinal block. Canadian Journal of Anaesthesia 1995;42(11):987-91.

[23] Akhter M, Mir AW, Ahmad B, et al. Dexmedetomidine as an adjunct to spinal anesthesia in urological procedures. Int J Contemp Med Res 2017;4(1):154-8. 